\title{
PRE-STARt: development of a diabetes prevention educational intervention for 12-14 year olds in five European countries
}

J. Troughton', J. Jarvis', D. Harrington², C. Edwardson², E. Brady', L. Gray³, S. Blüeher', I. Vergara Mitxeltorena ${ }^{5}$, R. Ribeiro6 ${ }^{6}$ A. Gerasimidi-Vazeou', M.J. Davies².

1. University Hospital of Leicester NHS Trust- UK, Leicester Diabetes Centre, Leicester, United Kingdom. 2. University of Leicester, Diabetes Research Centre, Leicester, United Kingdom. 3. University of Leicester, Department of Health

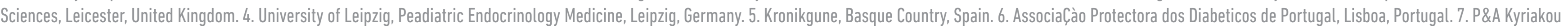
Children's Hospital, A' Department of Pediatrics, Athens, Greece.

\section{Introduction}

Type 2 diabetes (T2D) is a condition traditionally associated with old age. The prevalence is increasing in those under the age of 40 . Children and young people who develop T2D present with an extreme phenotype and they have poorer long-term outcomes compared to their peers with type 1 diabetes and older adults with T2D. The condition burdens the individual, the family unit, the health system and society in general as more young people battle to prevent micro- and macro-vascular complications in the prime years of their lives. For this reason there is a need to develop prevention strategies for young people and their families.

\section{Aim}

The aim of this work was to develop a T2D prevention programme in 12-14 year olds for use in five European sites (Germany, Greece, Portugal, Spain and UK).

\section{Method}

An established framework for developing this interactive educational programme was followed. Ideas from all sites regarding content and structure were gathered using the extant literature, from stakeholders and from the investigatory team.

This led to sites agreeing a draft programme outline of eight, 90 minute sessions.

Topics to be covered included: increasing physical activity (PA), sitting less, making healthier breakfast and snack choices and what it means to be healthy.

A document detailing the underpinning theories and philosophies of the programme was developed to standardise delivery across and within sites. Learning outcomes for each session were developed and a written curriculum was drafted, with supporting resources, using minimal narrative to allow for easy adaptation and translation. This allowed countries to make country specific changes to session content but not to the overall learning outcomes. A cycle of piloting and refinement was done in the UK and the curriculum was refined based on observations and feedback. Each site tested components of the programme as needed. Visits by the UK team to sites to discuss the curriculum and to provide educator training were invaluable to prevent misunderstanding.

\section{Results}

This work has resulted in a flexible curriculum with shared learning outcomes for sites to use with young people and their families. Each session includes a review of progress, topic-specific material, goal setting and an activity session for all family members. A commercial PA self-monitoring tool was included to supporting participants in achieving PA related goals. The following of a systematic approach to programme development has meant that the interactive educational programme is being tested within a feasibility study at each site.

\section{Conclusions}

Developing a standardised programme across countries is challenging. Agreeing on underpinning theories and philosophies as well as learning outcomes will ensure the programme is delivered in a similar spirit across and within sites.
PRE-STARt: Session Plan

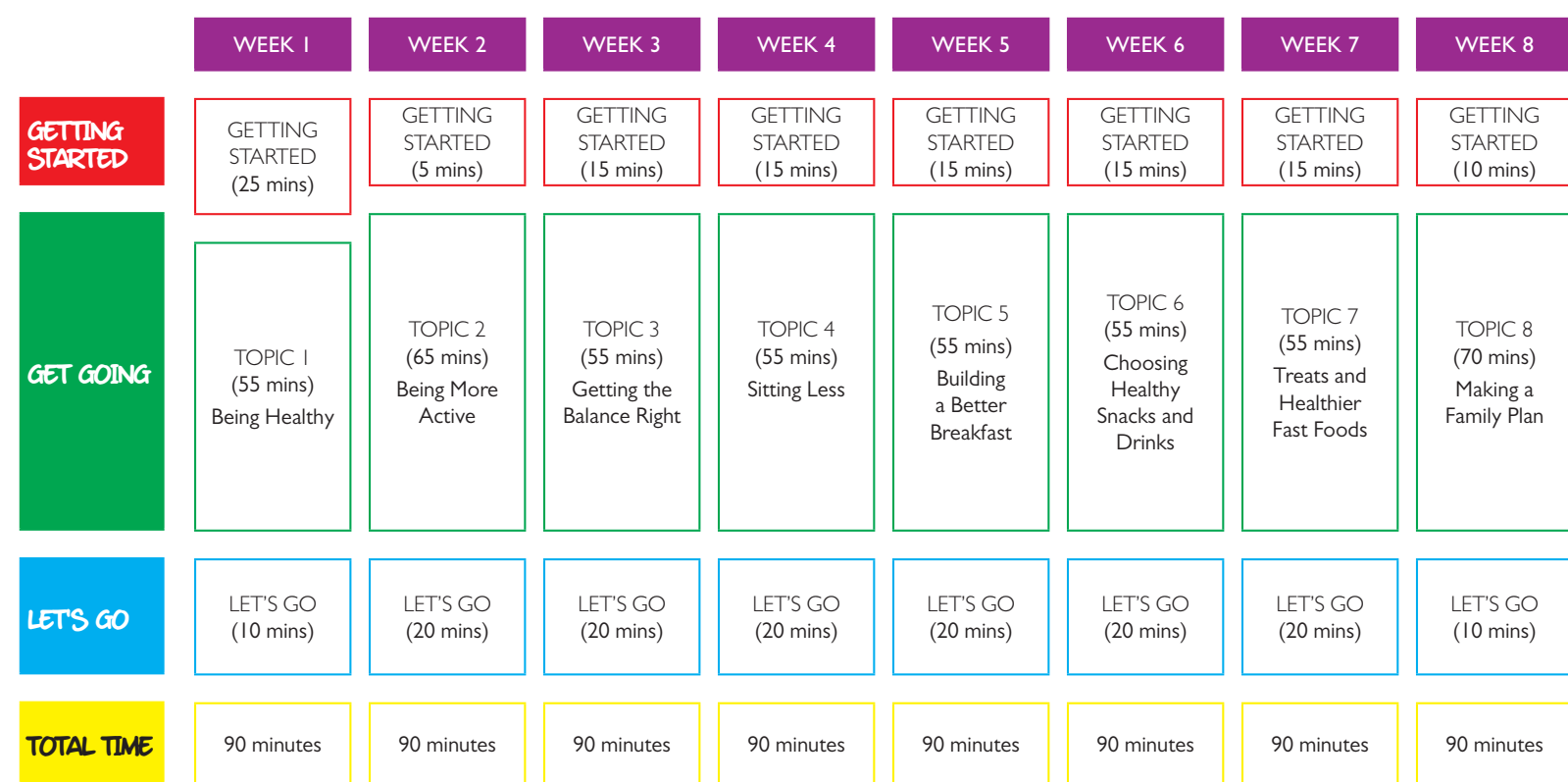

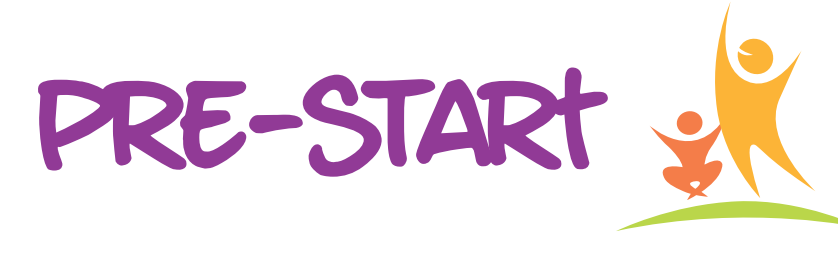
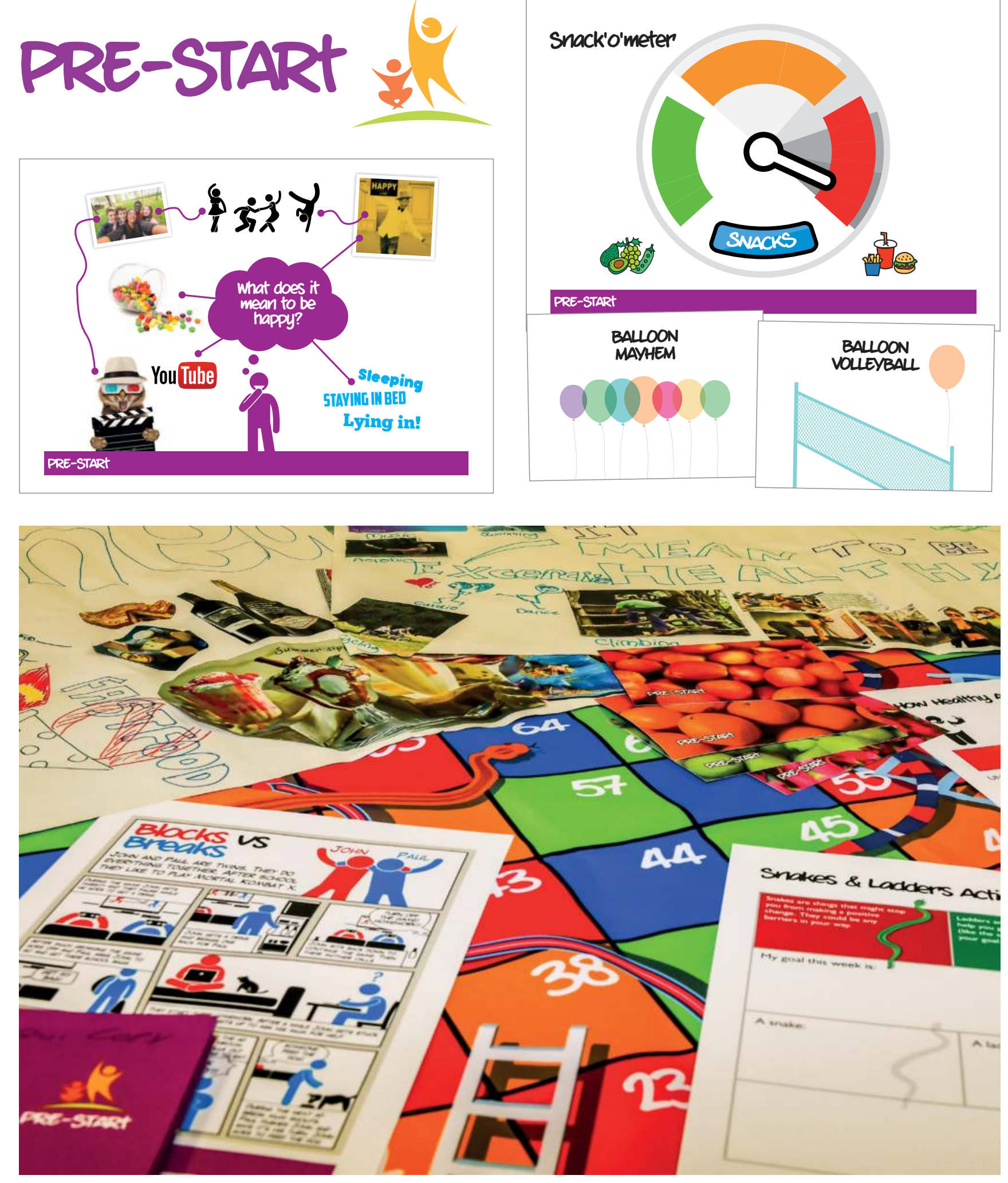

biodonostia In collaboration with: UNIVERSITAT LEIPZIG

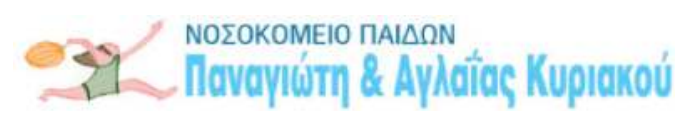
ogapdp Osakidetza

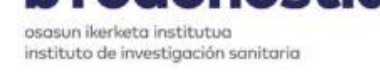

\section{.}

